FETAL AND NEONATAL EDITION

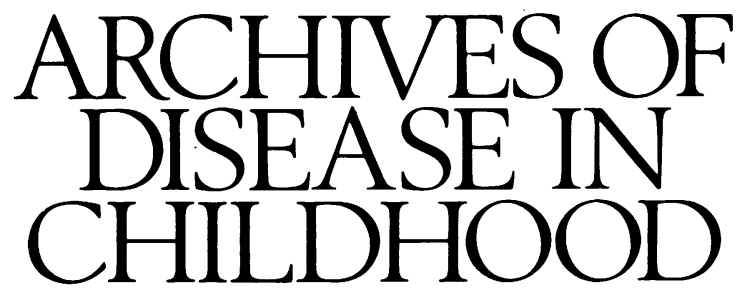

The fournal of the British Paediatric Association

\title{
Annotations
}

\section{Fetoplacental circulation in health and disease}

'The first time [in the year 1743] that I injected the vein of the naval string [cord] while the placenta adhered to the uterus, in separating these two parts it was evident that the injection had nowhere passed further than the placenta. ... From all these experiments and observations, which have been often repeated and diligently attended to with no other desire than to discover the truth, it seems incontestible that the human placenta, like that of the quadruped, is composed of two distinct parts, though blended together, viz, an umbilical, which may be considered as part of the foetus, and a uterine, which belongs to the mother.'

The Anatomy of the Gravid Uterus, William Hunter 1754

The 250th anniversary of the discovery of the fetoplacental circulation is characterised by a renewal of interest in the placenta, especially with the emergence of data suggesting its influence on adult health and disease. ${ }^{1}$ This review will consider the extent of our knowledge of the physiology and pathophysiology of the fetoplacental circulation, and attempt to provide a clinical perspective on these observations.

\section{Physiology of the fetoplacental circulation}

The metabolic demands of fetus at term are met through the haemochorial arrangement between maternal and fetal blood within the placenta. On the fetal side as much as $40 \%$ of cardiac output enters the umbilical circulation at term ${ }^{2}$; this arrangement implies very low resistance to blood flow in the umbilical circulation as it must 'compete' with the lower fetal body for aortic blood flow. The fetoplacental circulation is unique as it is not innervated, ${ }^{3}$ suggesting that the low resistance to blood flow is conferred by either vasomotor or anatomical mechanisms.

An expanding variety of substances are known to influence tone in vessels from the term placenta. ${ }^{45}$ Vasoconstrictor substances include thromboxane $A_{2}$ produced either by platelets or the umbilical vessels, ${ }^{6}$ angiotensin II $^{7}$ produced either within the fetal kidney ${ }^{8}$ or perhaps even within the placenta, ${ }^{910}$ and endothelin synthesised locally within the placenta. ${ }^{11}$

If low resistance to blood flow at term is brought about by the activities of vasoactive substances then vasodilator mechanisms must predominate. One likely candidate for this role is atrial natriuretic peptide (ANP) which is synthesised by the fetal heart from as early as 7 weeks of gestation. ${ }^{12}$ ANP is released by stretching of the heart in response to volume overload, and acts by dilating vascular smooth muscle and promoting diuresis. Release of ANP by the human fetus has been demonstrated in response to intravascular transfusion for rhesus disease. ${ }^{13}$ Biologically active ANP receptors have been characterised within fetoplacental vessels and shown to be functional within the range of circulating fetal ANP within the placenta. ${ }^{14}$ Thus ANP is a physiological endocrine signal between the fetal heart and the placenta in vivo. ${ }^{15}$

Another candidate vasodilator of the fetoplacental circulation is endothelium derived relaxing factor (EDRF). ${ }^{16}$ Nitric oxide synthase generates EDRF production from L-arginine within endothelial cells and this enzyme has recently been characterised within the human term placenta. ${ }^{17}$ Prostacyclin has anticoagulant and vasodilator properties ${ }^{18}$ and is synthesised by endothelial cells. However, a physiological role for prostacyclin within the placenta is uncertain as cyclo-oxygenase inhibition within the dually perfused human has no effect on fetoplacental vascular tone. ${ }^{19}$

The fetoplacental circulation is characterised by a progressive fall in vascular resistance as pregnancy advances. ${ }^{20}$ The majority of research to date on control of vascular tone within the placenta has been confined to the normal term placenta, but clearly studies which attempt to understand this observation are important. The expression of biologically active ANP receptors within fetoplacental vessels is reduced in preterm deliveries, ${ }^{14}$ suggesting that the placenta may become more responsive to the actions of ANP as pregnancy advances. The contractile response of the term umbilical artery to oxygen, which presumably ensures effective closure of the umbilical arteries at birth, ${ }^{21}$ is undetectable in umbilical arteries from spontaneous preterm births between 26-32 weeks of gestation. ${ }^{22}$ The significance of these findings are as yet difficult to interpret, but such data illustrate the importance of defining the relative role of individual vasoactive factors in the control of vasomotor tone.

An alternative and perhaps more rewarding approach is to view the control of blood flow within the fetoplacental circulation from an anatomical perspective. The fetoplacental circulation has a villous arrangement, beginning as muscularised stem arteries, branching up to 14 times and ending as long dilated capillary loops within the terminal villi; by term the fetal vascular surface area for gas and nutrient exchange is about $8 \mathrm{~m}^{2} .^{23}$ As pregnancy advances the more distal branches of the villous tree continue to branch as part of the process of placental 
'maturation' (in much the same way that alveoli continue to bud in the lung after birth). This continued development of the fetoplacental circulation may explain the reduction in fetoplacental vascular resistance as pregnancy advances, though at present the developmental anatomy of the human fetoplacental circulation is not well characterised.

\section{Pathophysiology of the fetoplacental circulation}

Doppler ultrasound has provided the obstetrician with a non-invasive method of assessing blood flow within the fetoplacental circulation. Abnormal waveforms (principally the loss of forward end diastolic flow velocity) in the umbilical arteries of many pregnancies complicated by either preeclampsia ${ }^{24}$ or severe intrauterine growth retardation (IUGR) ${ }^{2526}$ provide an important insight to their pathophysiology as these data suggest that fetoplacental perfusion is abnormal. These pathological pregnancies are often terminated by caesarean section in either the maternal or fetal interest, producing babies with a high rate of perinatal morbidity and mortality. ${ }^{27}$ The link between abnormal fetoplacental perfusion and pre-eclampsia/IUGR is therefore crucial to understand.

The numbers of stem villous arteries, as assessed by conventional light microscopy, have been found to be reduced in growth retarded pregnancies complicated by abnormal umbilical artery Doppler. ${ }^{28} 29$ Embolisation of the fetoplacental circulation in sheep can reproduce these Doppler findings in an acute setting, which has been used to advance the theory that stem villous arteries are somehow 'obliterated'. ${ }^{30}$ The reduction in circulating fetal platelet number observed in pregnancies complicated by IUGR has been taken to imply that they are the source of emboli in small fetoplacental vessels. ${ }^{31} 32$ However, no anatomical studies have been conducted to date to prove this association.

Thus it may be more likely that a disorder of vasomotor regulation is responsible for abnormal umbilical Doppler in pathological pregnancies. Endothelin concentration has been found to be raised in umbilical cord plasma from pregnancies complicated by IUGR. ${ }^{33}$ Many fetuses with IUGR are known to exist in a chronically hypoxic environment, ${ }^{25}$ which is known to stimulate production of endothelin in vitro. ${ }^{34}$ Chronic hypoxia probably activates other vasoactive systems, in particular the fetoplacental renin-angiotensin system. ${ }^{35}$ The biological action of angiotensin II may be enhanced in placentas from pregnancies where there is IUGR, ${ }^{36}$ which may result from an alteration in fetal intrarenal production of renin. ${ }^{8}$ Angiotensin II is a growth factor for smooth muscle cells, ${ }^{37}$ and it is of interest that proximal fetoplacental stem villous arteries are hypertrophied in placentas from some pregnancies complicated by IUGR. ${ }^{38}$

The vasomotor and anatomical theories of abnormal fetoplacental tone should not be viewed in isolation; it is very likely that they coexist and are responsible, in varying amounts, for the underlying disorder. There is a growing body of evidence indicating a derangement in the anatomy of the fetoplacental circulation in IUGR, ${ }^{39} 40$ and from pregnancies delivered at a high altitude. ${ }^{41}$ Maternal oxygen delivery to the developing placenta may therefore govern the subsequent anatomical and vasomotor control of the fetoplacental circulation.

Consequences of abnormal fetoplacental blood flow The pathophysiological mechanisms operating within the fetoplacental circulation of pregnancies complicated by either pre-eclampsia or IUGR may also be present in the systemic circulation of the fetus. It is of interest that low birth weight, and in particular a high placental/fetal weight ratio, may be linked to the development of hypertension in adult life. ${ }^{42-45}$ The adverse fetal environment which precipitated a preterm delivery (or perhaps even preterm birth itself) must somehow set in motion events which confer a high risk of cardiovascular disease in adult life.

One such mechanism may be chronic activation of the fetoplacental renin-angiotensin system. ${ }^{36}$ Angiotensin II is a vascular growth factor ${ }^{37}$ and therefore could cause relative 'overgrowth' of the placenta relative to its fetus. Moreover in the neonatal spontaneously hypertensive rat, inhibition of angiotensin II during the first few weeks of life has been shown to prevent the subsequent development of hypertension. ${ }^{46}$

Our understanding of the pathophysiology of the fetoplacental circulation in pregnancies with abnormal umbilical artery Doppler is only beginning to emerge. It is possible that the fundamental defect may be a failure of normal development of the fetoplacental circulation during early pregnancy: chronic hypoxia results and subsequently activates a variety of vasomotor mechanisms to produce a vicious circle. This sequence of events may finally 'programme' the fetus/neonate towards a greater risk of cardiovascular disease as an adult. Continuing research in this field is thus of unquestionable importance.

\section{J C P KINGDOM} LENA M MACARA

Department of Obstetrics and Gynaecology,

Queen Elizabeth Building,

Royal Infirmary

Glasgow G31 2ER

Department of Fetal Medicine,

M J WHITTLE

Birmingham Maternity Hospital,

Edgbaston,

Birmingham B15 2TG

1 Barker DJP. The fetal and infant origins of adult disease. London: British Medical Journal Books, 1992.

2 Rudolph AM, Heyman MA. Circulatory changes during growth in the fetal lamb. Circ Res 1972; 26: 289-99.

3 Reilly FD, Russell PT. Neurohistochemical evidence supporting an absence of adrenergic and cholinergic innervation in the human placenta and of adrenergic and cholinergic innervation
umbilical cord. Anat $\operatorname{Rec} 1977 ; 188: 277-86$.

4 Boura ALA, Walters WAW. Autocoids and the control of vascular tone in the human umbilicalplacental circulation. Placenta 1991; 12: 453-77.

5 Myatt $\mathrm{L}$. Control of vascular resistance in the human placenta. Placenta 1992; 13: 329-41.

6 Templeton A, Kingdom JCP, Whittle M, McGrath J. Contractile responses of the human umbilical artery from pregnancies complicated by hypertension and intrauterine growth retardation. Placenta 1991; 12: 439.

7 McQueen J, Jardine AG, Kingdom JCP, Templeton A. Interaction of angiotensin II and atrial natriuretic peptide in the human fetoplacental unit. Am F Hypertens 1991; 3: 641-4.

8 Graham PC, Kingdom JCP, Raweily EA, Gibson AAM, Lindop GBM. Distribution of renin-containing cells in the developing human kidney: an immunocytochemical study. Br $₹$ Obstet Gynaecol 1992; 99: 765-9.

9 Glance DG, Elder MG, Bloxam DL, Myatt L. The effects of the components of the renin-angiotensin system on the isolated perfused human placental of the renin-angiotensin system on the isolated pe

10 Keyurrangual V, Samani NJ, Craven DJ, Symonds EM. Expression of components of the renin-angiotensin system in human placenta and foetal membranes. Abstracts from Medical Research Society, October 1991.

11 Wilkes BM, Mento PF, Hollander AM, Maita ME, Sung S. Girardi EP. Endothelin receptors in human placenta: relationship to vascular resistance and thromboxane release. Am f Physiol 1990; 258: 864-70.

12 Wharton J, Anderson RH, Springall D, et al. Localisation of atrial natriuretic peptide immunoreactivity in the ventricular myocardium and conduction system of the fetal and adult heart. Br Heart f 1988; 60: 267-74.

13 Kingdom JCP, Ryan G, Whittle MJ, et al. Atrial natriuretic peptide: a vasodilator of the fetoplacental circulation? Am $\mathcal{f}$ Obstet Gynecol 1991; 165: $791-800$.

14 McQueen J, Kingdom JCP, Whittle MJ, Connell JMC. Characterization of atrial natriuretic peptide receptors in the human fetoplacental vasculature. Am f Physiol 1993; 264: H798-804.

15 Inglis GC, Kingdom JCP, Nelson DM, et al. Atrial natriuretic hormone: a paracrine or endocrine role within the human placenta? $\mathcal{f}$ Clin Endocrinol paracrine or endocrine

16 Myatt L, Brewer A, Brockman DE. The action of nitric oxide in the perfused human fetal-placental circulation. Am f Obstet Gynecol 1991; 164: 687-92.

17 Myatt L, Brockman DE, Eis ALW, Pollock JS. Immunohistochemical localization of nitric oxide synthase in the human placenta. Placenta 1993; 14: 487-95.

18 Vane JR, Anggard EE, Botting RM. Regulatory mechanisms of the vascular endothelium. $N$ Engl $₹$ Med 1990; 323: 27-36. 
19 Jacobson RL, Brewer A, Eis A, Siddiqi TA, Myall L. Transfer of aspirin across the perfused human placental cotyledon. Am $\mathcal{F}$ Obstet Gynecol 1991; 165: 939-44.

20 Hendricks S, Sarensen TK, Wong KY, et al. Doppler umbilical artery waveform indices - normal values from fourteen to forty-two weeks. Am $\mathcal{f}$ Obstet Gynecol 1989; 161: 761-5.

21 Templeton AGB, Whittle MJ, McGrath JC. The role of endogenous thromboxane in contractions to U46619, oxygen, 5-HT and 5-CT in the human isolated umbilical artery. Br f Pharmacol 1991; 103: 1079-84.

22 Templeton AGB, Kingdom JCP, Whittle MJ, McGrath JC. Contractile responses of the human umbilical artery from pregnancies complicated by responses of the human umbilical artery from pregnancies con

23 Leiser R, Kosanke G, Kaufmann P. Human placental vascularization: structural and quantitative aspects. In: Soma $\mathrm{H}$, ed. Placenta - basic science for clinical application. Tokyo: Karger publications, 1991.

24 Fairlie FM, Moretti M, Walker JJ, Sibai BM. Determinants of perinatal outcome in pregnancy-induced hypertension with absence of end-diastolic frequencies. Am $₹$ Obstet Gynecol 1991; 164: 1084-9.

25 Laurin J, Lingman G, Marsal K, Persson P-H. Fetal blood flow in pregnancies complicated by intrauterine growth retardation. Obstet Gynecol 1987; 69: 895-902.

26 Nicolini U, Nicolides P, Fisk NM. Limited role of fetal blood sampling in prediction of outcome in intrauterine growth retardation. Lancet 1990; 336: 768-82.

27 Escobar GJ. Prognosis of surviving very low birthweight infants: still in the dark. Br ₹ Obstet Gynaecol 1992; 99: 1-4.

28 Giles WB, Trudinger BJ, Baird P. Fetal umbilical artery flow velocity waveforms and placental resistance: pathological correlation. $\mathrm{Br}$ f Obstet Gynaecol 1985; 92: 31-8.

29 McCowan LM, Mullen BM, Ritchie K. Umbilical artery flow velocity waveforms and the placental vascular bed. Am $\mathcal{f}$ Obstet Gynecol 1987; 157: 900-2.

30 Morrow RJ, Bull S, Ritchie JWK. Pathological basis of abnormal Doppler waveforms. In: Pearce $M$, ed. Doppler ultrasound in perinatal medicine. London: Churchill Livingstone, 1992.

31 Wilcox GR, Trudinger BJ. Fetal platelet consumption: a feature of placental insufficiency. Obstet Gynecol 1991; 77: 616-21.

32 Van den Hof MC, Nicolaides KH. Platelet count in normal, small, and anemic fetuses. Am ₹ Obstet Gynecol 1990; 162: 753-9.
33 Hartikainen-Sorri A-L, Vuolteenaho O, Leppaluoto J, Ruskoaho H. Endothelin in umbilical artery vasospasm. Lancet 1991; 337: 619.

34 Douglas SA, James S, Hiley CR. Endothelial modulation and changes in endothelin presser activity during hypoxia in the rat isolated perfused superior mesenteric arterial bed. Br $\mathcal{f}$ Obstet Gynaecol 1991; 103: 1441-8.

35 Robillard JE, Weitzman RE, Burmeister L, Smith FG. Developmental aspects of the renal response to hypoxemia in the lamb fetus. Circ Res 1981; 48: $128-38$

36 Kingdom JCP, McQueen J, Connell JMC, Whittle MJ. Fetal angiotensin II levels and vascular (type I) angiotensin receptors in pregnancies complicated by intrauterine growth retardation. Br 7 Obstet Gynaecol 1993; 100: 476-83.

37 Lever AF. Slow pressor mechanisms in hypertension: a role for hypertrophy of resistance vessels. $\mathcal{F}$ Hypertens $1986 ; 4$ : 515-24.

38 Fok RY, Pavlova Z, Benirschke K, Paul R, Platt LD. The correlation of arterial lesions with umbilical artery Doppler velocimetry in the placentas of small-for-dates pregnancies. Obstet Gynecol 1990; 75: 578-83.

39 Abitol MM, La Gamma, Demeter E, Cipollina CM. Umbilical flow in the normal and pre-eclamptic placenta. Acta Obstet Gynecol Scand 1987; 66: 689-94.

40 Nordenvall M, Ullberg I, Laurin J, Lingman J, Sandstedt B, Ulmsten U. Placental morphology in relation to umbilical artery blood velocity waveforms. Eur F Obstet Gynecol Reprod Biol 1991; 40: 179-90.

41 Mironov VA, Katcher OV, Lebedeva IM. Three-dimensional morphology of placental villous tree and anthropometric estimations of newborns from placental villous tree and anthropometric estimations of newb

42 Gennser G, Rymark P, Isberg PE. Low birthweight and risk of high blood pressure in adulthood. $B M$ F 1988 ; $298: 1498-9$.

43 Williams S, St George IM, Silva PA. Intrauterine growth retardation and blood pressure at age seven and eighteen. $\mathcal{F}$ Clin Epidemiol 1992; 45: 1257-63.

44 Barker DJP, Bull AR, Osmond C, Simmonds SJ. Fetal and placental size and risk of hypertension in adult life. $B M \mathcal{F} 1990 ; 301: 259-62$

45 Barker DJP, Osmond C, Golding J, Kuh D, Wadsworth MEJ. Growth in utero, blood pressure in childhood and adult life, and mortality from cardiovascular disease. BMF 1989; 298: 564-7.

46 Morton J, Beattie EC, MacPherson F. Angiotensin II receptor antagonist Losatan has persistent effects on blood pressure in the young spontaneously hypertensive rat: lack of relation to vascular structure. $\mathcal{F}$ Vasc Res 1992; 29: 264-9.
TORCH (toxoplasmosis, rubella, cytomegalovirus, and herpes) screening has become almost synonymous with the investigation of an unexpected small for dates and/or premature infant with or without other abnormalities, and of apparently unknown cause. If no further direction is given to the house officer, he or she will embark on a series of unnecessary tests and may compound the error by sending inappropriate samples. The futility of such an approach has already been highlighted in a recent editorial. ${ }^{1}$ The aim of this annotation is to further hasten the demise of the 'TORCH screen' by considering three specific areas. Firstly, to consider the presentation of congenital infections and to stress that there are now more congenital infections than were originally encompassed by the term TORCH. Rather than expand the screening test clinicians should be aware that many infections present with specific clinical pictures and they should direct investigations accordingly. Secondly, to emphasise the rarity of any congenital infection and thus the poor yield of the blunderbuss approach of the TORCH screen. Thirdly, to consider whether antenatal diagnosis will reduce or even eliminate the need for neonatal TORCH screening.

\section{(1) Postnatal presentation}

To request a TORCH screen on a neonate suggests that certain abnormalities are characteristic of congenital infection and the clinical presentation of different agents is similar. Neither supposition is watertight. For example, although growth retardation can occur in congenital herpes $^{2}$ or syphilis, 50 infants with cytomegalovirus infection had weights and head circumferences that did not differ significantly from those of 97 controls. ${ }^{3}$ In addition, HIV infection, except in babies of seropositive mothers from Zaire, ${ }^{4}$ has not been associated with growth retardation..$^{5}$ Prematurity is not a sine qua non of congenital infection, although typical of congenital syphilis, it is not increased by cytomegalovirus infection. Investigation of a small for dates or premature infant is extremely unlikely to identify any of the congenital infections. Only 10 to $15 \%$ of infants infected by toxoplasmosis during pregnancy have abnormalities in the neonatal period, ${ }^{6}$ even though $50 \%$ develop neurological sequelae or chorioretinitis by the age of 20 years. ${ }^{7}$ Parvovirus infection is associated with nonimmune hydrops, but rarely causes congenital malformation, ${ }^{8}$ indeed there is only one report of a fetal eye anomaly. ${ }^{9}$

Clinical signs that are presumed to be a non-specific clue to congenital infection may, in fact, be characteristic of one particular agent. Syphilis presents with many of the signs expected from a TORCH infection, a vesicular and erythematous skin rash, petechiae, severe non-haemolytic anaemia, and hepatosplenomegaly. In addition, the infant may suffer intestinal malfunction due to syphilitic enterocolitis, respiratory distress because of prematurity and/or pneumonia alba. The associated condylomata are, however, specific as are, in $95 \%$ of infants with congenital syphilis, the characteristic long bone changes (symmetrical metaphyseal lesions, horizontal bands of increased/ decreased radiodensity, and peripheral porosis. ${ }^{10}$ The diagnosis will be further advertised by the peeling of the soles of the feet and palms of the hands and can be confirmed by isolation of the spirochaete from the vesicular lesions. Reliance on the clinical signs described by the TORCH syndrome to identify congenitally infected infants could result in underdiagnosis of other including more recently described infections. Infants with listeriosis may present solely with septicaemia or an unusual pneumonia $^{11}$ and this infection should be considered in the differential diagnosis of any infant presenting with septicaemia and/or pneumonia, particularly if premature labour has been complicated by meconium stained liquor. 